Review

\title{
Epigenetics of Sleep Disruption
}

\author{
Parisa Gazerani ${ }^{*}$
}

Laboratory of Molecular Pharmacology, Department of Health Science and Technology, Faculty of Medicine, Aalborg University, 9220 Aalborg East, Denmark; E-Mail: gazerani@hst.aau.dk

* Correspondence: Parisa Gazerani; E-Mail: gazerani@hst.aau.dk

Academic Editor: Bart Ellenbroek

Special Issue: Sleep and Health

OBM Neurobiology

2020 , volume 4 , issue 3

doi:10.21926/obm.neurobiol.2003071
Received: June 27, 2020

Accepted: August 25, 2020

Published: September 08, 2020

\begin{abstract}
Sleep plays an important role in maintaining brain function, memory consolidation, hormonal balance, immune system function, growth, and repair. The physiological and psychological effects of disruptions in sleep highlight its importance in human health and wellness. Epigenetic roles are proposed in sleep, and circadian regulation, but only a limited number of studies have determined the mechanism that underlies the epigenetics of environmental factors interacting with the sleep, particularly the ones related to sleep disruption. Therefore, studying epigenetics of sleep and sleep disorders can help elucidate the way these factors promote or inhibit sleep disorders, potentially guiding the development of precision medicines or preventive strategies. However, before discovering useful epigenetic-based interventions for sleep disorders, we need to overcome many challenges. As a relatively new field, there are unmet needs that call for further investigation of epigenetic mechanisms underlying sleep disruption. This review focuses on the current status of epigenetic mechanisms in sleep disruption (e.g., sleep deprivation and circadian dysregulation), which highlights a great potential of both animal and human studies to explain the disturbances in sleep, associated consequences, and novel therapeutic potentials. Translating the epigenetic research in sleep disturbances can eventually lead to better diagnosis, prognosis, prevention, and therapy in the clinics.
\end{abstract}

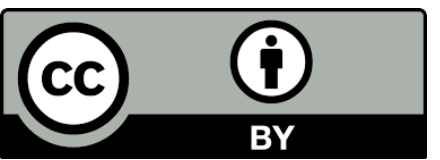

(C) 2020 by the author. This is an open access article distributed under the conditions of the Creative Commons by Attribution License, which permits unrestricted use, distribution, and reproduction in any medium or format, provided the original work is correctly cited. 


\section{Keywords}

Epigenetics; sleep; sleep deprivation; DNA methylation; acetylation; LncRNAs, miRNAs; epigenome-wide association studies

\section{Sleep}

Sleep is regulated by homeostatic and circadian mechanisms and is a reversible state. During sleep, a low sensory response with motor immobility is observed throughout the animal kingdom, with only a few exemptions [1]. It is defined as a fundamental element of life, with many studies collectively demonstrating its essential role in health. Several theories are merged to explain the function of sleep in decreasing the energy demands [2], restoring cellular processes [3], maintaining immune health [4], and regulating the communication between neurons [5]. Neuronal-based studies have highlighted the significant role of sleep in memory consolidation [6]. Achieving good sleep quality (e.g., low sleep latency, low number of awakenings, low waking after sleep onset, and better sleep efficiency) [7] and duration [8,9] is necessary for overall health and well-being. Poor sleep is linked to a diverse range of health issues, including developmental impairments, somatic and cognitive deficits, and rapid aging. Sleep plays a multidimensional role in one's physiological and psychosocial aspects of life and is affected by a diverse range of internal and external parameters. Cellular mechanisms underlying the sleep function are being elucidated gradually. In humans, sleep diversity exists between the individuals and also within an individual in their life span, which proposes the role of genetic variations among individuals. However, environmental and lifestyle factors also contribute to this diversity.

Sleep in mammals consists of cycles of rapid eye movement (REM) and different stages of nonREM (NREM), which reflect the cortical activity patterns and can be monitored by electroencephalography (EEG). During sleep, a coordinated neural activity is seen in the hippocampus [10], where certain patterns of interactions are observed between CA1 pyramidal neurons and inhibitory interneurons [11]. It is proposed that the coordination between hippocampal and extra-hippocampal oscillatory activity during sleep promotes memory consolidation that is formed during wakefulness [12]. Sleep-wake cycles are regulated by the circadian clock, which is the master pacemaker in the suprachiasmatic nucleus that coordinates complex physiological processes and behaviors with the circadian rhythmicity [13]. Circadian rhythm is derived from the $24 \mathrm{~h}$ day and night (light-dark) cycle that accompanies biological cycles, including fasting-feeding, body temperature, hormone secretion, and sleep-wake. Also, both the internal feedback loop and the external environment interact with the circadian rhythms. Several chronotypes (preferred time of day for daily activities) exist while the two extreme preferences are termed as morningness and eveningness [14, 15], and these two chronotypes are reported to have genetic components $[16,17]$, i.e., they express two circadian clock-regulated genes Per3 and Nr1d2. Ingram et al. in 2016 [16] measured the expression of Per3 and Nr1d2 in hair follicle samples and assigned the RNA chronotypes- morningness and eveningness to the participants. A difference was identified between these two groups even in decision-making tasks, where only a 3-hour phase difference in molecular clockwork was sufficient to influence the decision-making, highlighting the effects of endogenous clock function in human performance [16]. Chronotype 
influences both physical and mental health $[18,19]$ with cortisol levels also being different in early and late hours preferring people. Early chronotype presents with a more pronounced adrenocortical activation after waking up compared to the late chronotype [14]. Disruption in cortisol and melatonin rhythms [20] are known to impair circadian rhythms and play roles in disorders associated with sleep [21, 22], impaired glucose tolerance, or low level of alertness [23]. Polymorphisms and mutations of circadian genes were identified and reported with evidence highlighting the transcription of circadian clock genes being epigenetically regulated by the changes in DNA methylation, histone modifications, and structural chromatin alterations [24]. Most of the epigenetic modifications are driven by the external environment and lifestyle. Lack of sleep and sleep disturbances are common around the globe $[25,26]$. For example, at least $7 \mathrm{~h}$ of sleep per night is recommended for adults, but the data reports that more than $30 \%$ of adults in the United States have an insufficient sleep [27]. In Finland, a similar trend was reported with onethird of the adult population experiencing sleep difficulties [28], where $25 \%$ reported a sleep of 6 $\mathrm{h}$ or less per night $[26,28]$ and up to $45.3 \%$ were affected by insomnia symptoms, according to a previous study [28]. Shift work, for example, night shift and an early morning shift, is a common reason for insufficient sleep. Working in shift leads to misalignment in circadian rhythms, homeostasis imbalance, and shortened sleep time by 1 to $4 \mathrm{~h}$ [29]. Indeed, shift work disorder (SWD) [30] is a medical condition characterized by complaints of excessive sleepiness or insomnia, accompanied by a reduction in sleep duration with over one-third of shift workers suffering from this condition [31, 32]. Epidemiological evidence shows that disrupted sleep contributes to several health issues [33], specifically in the aging societies, including type 2 diabetes [34], cardiovascular diseases, neurodegeneration, depression, cognitive, and emotional dysfunction [35]. Sleep disruption can either be a single acute disruption, repeated disruptions, or even a lifetime disruption [36]. Therefore, sleep must be looked upon as an important state that has a multifaceted influence on health and well-being [37] and all aspects of sleep must be taken into account such as duration, timing, pattern, and quality because they can affect cellular structure, gene expression, metabolic and hormone regulation, mood, alertness, and quality and longevity of life. Over the last decade, attempts have been made for a better understanding of underlying mechanisms that determine the consequences of sleep disruption and experimental studies are conducted in both laboratory animals and humans to address the unanswered questions in the field. The study designs are now modified to include different modalities, describing the consequences and mechanisms of sleep loss under the chronic sleep disruption, which mirrors the current condition of many modern societies. Models for continuous, intermittent, or stagedependent sleep deprivation are applied for partial or total sleep deprivation (TSD) in animals and humans [37-39]. Advancing technologies have now permitted the identification of mechanisms underlying sleep disturbances and its multidimensional consequences such as the effect on brain cells, circuits, and metabolism shifts. However, several areas are still open for investigation, such as the activation mechanism of compensation or rescue and also questions about whether and how the adaptation occurs and failing of some processes in this regard [37].

The growing literature shows that insufficient sleep promotes epigenetic modifications and both acute and chronic sleep deprivation produces broad changes in epigenetic markers and patterns of gene transcription in animals [40-43] and humans [44, 45]. Targeting epigenetic factors have been challenging for many health conditions, such as cancer, psychiatric disorders, and 
neurodegenerative diseases. Therefore, these strategies could ultimately result in future interventions to prevent or treat sleep disruptions.

\section{Epigenetics of Sleep}

The term "epigenetic" means "in addition to changes in genetics" and this includes any process that alters gene activity without changing the DNA sequence. Epigenetic theory mainly focuses on the interaction between the environment and gene expression. Epigenetic markers such as genomic imprinting, DNA methylation, histone modifications, and non-coding RNAs were identified in several human health conditions and related disorders [46-49]. Although epigenetic modifications can be transmitted from parents to their offspring [50,51], maintaining itself through the generations $[52,53]$, some changes do reverse. DNA methylation and histone modification [54] make direct structural modifications influencing the gene expression. In contrast, non-coding RNAs are transcribed from DNA but not translated into protein. These functional RNA molecules regulate gene expression at the transcriptional and post-transcriptional levels [54]. miRNAs are emerging as diagnostic biomarkers in many human disorders, such as sleep apnea [55], neurodegenerative disorders [56], and pain [57-59].

DNA methylation is studied extensively in cancer [60] with first reports [61] highlighting the alterations of DNA methylation occurring throughout the genome of various cancer tissues compared to the normal tissues. The majority of these cancer-linked alterations were demonstrated by hypomethylation [62], but gradually it became evident that hypermethylation [63] also occurred in many cancers. Biological significance and clinical relevance of DNA methylation are increasingly being notified in cancer [64] and conditions such as aging [65] or even other disorders, namely, neurodegenerative and cerebrovascular disorders [66].

Besides DNA methylation [67], chromatin, a complex of histones, proteins, and DNA tightly bundled into the nucleus, can also be modified [68] by acetylation, enzymes, and some forms of RNA, such as microRNAs and small interfering RNAs [69]. After the modification, chromatin structure is altered, influencing the gene expression [70].

Another form of epigenetic inheritance is genomic imprinting, which is known in mammals, plants, and insects [71] and is defined as the regulation of a gene or chromosomal region depending on the sex of the transmitting parent [71]. The imprinted genes in the mammals are expressed in the parent-of-origin in a specific manner, playing an important role in the embryonic and extraembryonic growth and development and some human diseases, such as BeckwithWiedemann syndrome (BWS) and Russell-Silver syndrome (RSS) [72].

In the generation and regulation of the sleep-wake cycle, a complex interaction exists between neuroanatomical, neurochemical, neurophysiological, and genetic endogenous elements [73]. It is known that the environment plays a major role in the life of mammals and determines their developmental, physiological, or behavioral changes. It was proposed that external factors (e.g., light, darkness, diet, noise, heat, cold [74]), through the epigenetic mechanisms, might also contribute to circadian controlling of sleep and potentially be linked to sleep disturbances or disorders $[75,76]$.

Since the epigenetic mechanisms underlying the circadian regulation and sleep disorders is a broad-spectrum topic falling beyond the purpose of this review, we have mainly presented the epigenetic mechanisms underlying sleep disruption. We refer the readers to delve into excellent 
reviews available in the literature if interested in genetics and epigenetics of circadian regulation and sleep disorders, such as sleep apnea [77-80].

\subsection{Examples of Epigenetic Alterations in Sleep Deprivation}

We still have a limited understanding of epigenetic factors, onset, and underlying mechanisms in sleep-wake disturbances, sleep disorders, and associated chronobiological disturbances [13]. It is proposed that epigenetics and sleep are interrelated, but we still do not know if connections are causal, modulatory, or correlative [81]. Hence, several hypotheses have emerged [13], where epigenetic pathways directly cause sleep-wake disorders by deregulating the circadian clock. Insomnia and excessive sleepiness are the most common sleep disturbances [82, 83], with literature indicating epigenetics to be related to these conditions [45, 84]. DNA methylation, histone modifications, and chromatin remodeling are regulated by the circadian clock [13, 85]. A review article [86] has also presented the epigenetic markers of sleep deprivation from the findings of animal and human studies.

\subsubsection{DNA methylation}

The addition of a methyl group to a cytosine-guanine dinucleotide (CpG) is termed as DNA methylation and is one of the epigenetic modifications. Many studies have provided evidence that DNA methylation is affected by sleep [13, 42, 86-88]. Massart et al. [42] demonstrated that acute sleep deprivation in mice resulted in a remarkable expression of Dnmt3a1 and Dnmt3a2 genes. Narwade et al. [41] analyzed the transcriptome and reported altered expression of memory and neurotransmission associated genes in rats deprived of REM sleep. Another study has shown that twins with different diurnal preferences presented different DNA methylation patterns [84]. DNA methylation patterns are also found to be different in 52 genes in individuals who sleep less than $6.8 \mathrm{~h}$ (short sleepers) compared to those who sleep more than $7.8 \mathrm{~h}$ (long sleepers) [89]. In 2011, Zhu et al. [90] reported hypermethylation of cryptochrome circadian clock 2 (CRY2) and hypomethylation of CLOCK in the long-term night-shift workers. Four years later, Cedernaes et al. [88] reported the occurrence of DNA methylation following one night of sleep deprivation in men. The results from this study showed that CpG sites in period circadian clock 1 (PER1) and CRY1 promoter were significantly hypermethylated in adipose tissue samples obtained from sleepdeprived men. However, no difference was found in gene expression, proposing a potential gap time following the DNA methylation, which can be explained by the potential requirement for more changes. For example, the contribution of several $\mathrm{CpG}$ sites or other mechanisms such as histone modifications or contribution of non-coding RNAs [88]. Nilsson et al., in 2016 [45] performed a genome-wide DNA methylation study and found that 269 probes were significantly altered in blood samples of sleep-deprived healthy men and to identify the potential genes with altered expression and DNA methylation changes following the sleep deprivation, the authors of this study correlated their results with Möller-Levet et al. [91]. The correlation showed that one CPG site with decreased DNA methylation in the Inhibitor of growth 5 (ING5) gene correlated to a similar decrease in expression of ING5 [45].

These studies demonstrate that changes in DNA methylation occur in response to sleep deprivation and can help identify the epigenetic pathways affected by sleep loss. Further 
investigations are required to define the patterns of sleep-specific DNA methylation and its consequences [86].

\subsubsection{Histone Modification}

Histones can be modified [92] by methylation on lysine or arginine residue, but the methylation is mostly observed in histone tails $\mathrm{H} 3$ and $\mathrm{H} 4$ at lysine residue. Histone methylation can be associated with either transcriptional repression or activation, depending on the position of the residues modified and the number of methyl groups. Histone methylation is mediated by chromatin remodelers, including histone methyltransferases, histone lysine demethylases (KDMs), and other histone-modifying enzymes. Histone methylation and demethylation play an important modulatory role in the chromatin restructuring and RNA transcription, hence, controlling a diverse range of biological processes [92]. For example, studies have suggested that compounds such as 3deazaneplanocin A (DZNep) inhibit histone trimethylation of lysine 27 on histone H3 and lysine 20 on histone H4. DZNep is shown to control the sleep-wake cycle and release sleep-related neurochemicals via the histone methylation process [93].

Histone can also be acetylated by the enzyme histone acetyl-transferase (HAT), while deacetylation reactions are handled by histone deacetylase (HDAC). Histone acetylation reduces the interaction between histone and DNA, leading to the loosened chromatin conformation, which further facilitates transcriptional events. Histone acetylation is required in the regulatory process of gene expression, and it is shown that maintenance of circadian rhythm and sleep homeostasis is modulated by circadian genes, where the gene expression is regulated by histone modifications. Disrupted sleep homeostasis was reported in the mice models lacking in circadian genes [94], and since sleep deprivation alters the circadian gene expression, histone modification can be one of the potential underlying mechanisms. However, only a few studies have looked into histone acetylation after the occurrence of sleep deprivation. Duan et al. [40] analyzed the samples of the hippocampus from sleep-deprived rats and identified reduced acetylated histones at BDNF promoter IV. This observation was consistent with a previous study by Guzman-Marin et al. [95], who showed a reduced BDNF transcription and translation following prolonged sleep deprivation state. Future studies are required to identify the epigenetic markers present on the chromatin that are altered by sleep loss [86], eventually leading to the identification of sleep-specific biomarkers and targeting sleep loss disorders.

\subsubsection{Non-Coding RNAs}

As their name suggests, non-coding RNAs are the molecules that are transcribed from DNA but do not code for proteins. Several types of non-coding RNAs exist that are classified into two large groups based on their size: long non-coding RNAs (IncRNAs) and microRNAs. In recent years, a growing number of publications are available on the potential role of these molecules in health and disease [96, 97].

LncRNAs are $>200$ base-pairs, which can modify the structure of chromatin in the nucleus and alter gene expression [98]. It is identified that certain IncRNAs encode micro peptides that are found in the brain [99], opposing the commonly accepted term of being non-coding. LncRNAs are also associated with the circadian genes. For example, the ablation of IncRNA 116HG [100] causes dysregulation of CLOCK, Cry1, and Per2. In 2016, Davis et al. [101] reported differential expression 
of several IncRNAs following sleep deprivation. Although the roles of IncRNAs in the diseases of the central nervous system are being clarified increasingly [102], there is no explanation regarding the associated function of these IncRNAs affected by sleep deprivation [86].

MicroRNAs are small molecules of $\sim 22$ nucleotides and are abundant in the brain, where they associate with neurological processes such as synaptic plasticity [103, 104]. MicroRNAs are also associated with sleep deprivation with mir-132 [105] and miR-138 [106] being found in sleepdeprived rats. A genome-wide study by Davis et al. [107] reported significant alterations in let-7b and miR-125a in the brain following sleep deprivation. Table 1 presents examples of altered noncoding RNAs that follow sleep deprivation.

To identify the non-coding RNAs in the epigenetic mechanisms underlying the sleep disruption in future studies, it is suggested to perform the RNA-sequencing analyses along with the validation by cloning [86].

Table 1 Examples of altered non-coding RNAs following sleep deprivation.

\begin{tabular}{|c|c|c|}
\hline Study & Outcome & Reference \\
\hline $\begin{array}{l}\text { Sleep deprivation in mice } \\
\text { (Male homozygous P2X7RKO } \\
\text { mice, and wild type mice) }\end{array}$ & $\begin{array}{l}\text { In wild type mice, sleep deprivation } \\
\text { increased hypothalamic } \\
\text { 4930470G03Rik, A230107N01Rik, } \\
\text { C130021/20Rik, Gm17354, and } \\
\text { decreased A430010J10Rik } \\
\text { expression } \\
\text { In P2X7RKO mice, sleep deprivation } \\
\text { increased only 6820431F20 levels } \\
2 \text { potential IncRNA targets related to } \\
\text { sleep were identified: } \\
\text { 9430037G07Rik and Gm15832 }\end{array}$ & $\begin{array}{l}\text { Davis et al., } 2016 \\
{[101]}\end{array}$ \\
\hline $\begin{array}{l}\text { Sleep deprivation in rats (Male } \\
\text { Sprague-Dawley rats) }\end{array}$ & $\begin{array}{l}\text { let-7b, miR-138, miR-125a are } \\
\text { involved in sleep regulation } \\
\text { miRNAs expression differs based on } \\
\text { time of the day (end of dark } \\
\text { compared with the end of light), let- } \\
\text { 7b, miR-138, miR-125a higher levels } \\
\text { were found in pre-light onset. } \\
\text { miRNAs expression differs based on } \\
\text { brain region (the highest } \\
\text { concentrations in the hippocampus, } \\
\text { moderate in the hypothalamus, and } \\
\text { prefrontal cortex, and lower in the } \\
\text { occipital and somatosensory }\end{array}$ & $\begin{array}{l}\text { Davis et al., } 2012 \\
{[106]}\end{array}$ \\
\hline
\end{tabular}




\begin{tabular}{|c|c|c|}
\hline & cortices) & \\
\hline $\begin{array}{l}\text { Sleep deprivation in rats (Male } \\
\text { Sprague-Dawley rats) }\end{array}$ & $\begin{array}{l}\text { miRNA-132 is involved in sleep } \\
\text { regulation } \\
\text { Spontaneous brain levels of miRNA- } \\
132 \text { depend on brain site } \\
\text { (hippocampus, prefrontal cortex, } \\
\text { somatosensory cortex, and } \\
\text { hypothalamus) and time of day } \\
\text { miRNA-132 was highest at the } \\
\text { prefrontal cortex and at dawn }\end{array}$ & $\begin{array}{l}\text { Davis et al., } 2011 \\
\text { [105] }\end{array}$ \\
\hline $\begin{array}{l}\text { Patients with major depression } \\
\text { affected by late insomnia ( } 359 \\
\text { major depression patients and } \\
341 \text { controls) }\end{array}$ & $\begin{array}{l}\text { miR-182 is involved in insomnia } \\
\text { miR-182 inhibits Adenylate Cyclase } 6 \\
(A D C Y 6), C L O C K \text {, and DSIP } \\
\text { expression; } \\
\text { the abnormal processing of pre-miR- } \\
182 \text { in patients carrying the T allele } \\
\text { of the rs76481776 polymorphism } \\
\text { may contribute to the dysregulation } \\
\text { of circadian rhythms in these } \\
\text { patients with insomnia }\end{array}$ & $\begin{array}{l}\text { Saus et al., } 2010 \\
{[108]}\end{array}$ \\
\hline $\begin{array}{l}\text { Sleep deprivation in mice (Male } \\
\text { mice } 57 \mathrm{BL} / 6 \mathrm{~J}, \mathrm{AKR} / \mathrm{J} \text {, and } \mathrm{DBA} / 2 \mathrm{~J} \text { ) }\end{array}$ & $\begin{array}{l}10 \text { miRNAs expression altered with } \\
\text { sleep deprivation; upregulated (miR- } \\
410,-212,-29 c,-29 b-2 \text {, and }-708 \text { ) } \\
\text { and downregulated (let-7e, miR- } \\
137,-22,-219-2 \text {, and }-99 a) \\
\text { miR-410, }-212,-29 c \text {, and }-151 \text { were } \\
\text { verified; potential targets were } \\
\text { found for miR-151 and a tendency } \\
\text { for miR-212 }\end{array}$ & $\begin{array}{l}\text { Mongrain et al., } \\
2010[109]\end{array}$ \\
\hline $\begin{array}{l}\text { Sleep deprivation in rats (Male } \\
\text { Sprague Dawley rats) Genome- } \\
\text { wide study }\end{array}$ & $\begin{array}{l}50 \text { miRNAs were affected by sleep } \\
\text { loss. } \\
\text { Let-7b and miR-125a significantly } \\
\text { changed in all four brain regions } \\
\text { The number of miRNAs and their } \\
\text { expression affected by the sleep loss } \\
\text { were brain region dependent. In } \\
\text { hippocampus, miRNA expression }\end{array}$ & $\begin{array}{l}\text { Davis et al., } 2007 \\
{[107]}\end{array}$ \\
\hline
\end{tabular}


increased but in somatosensory and prefrontal cortices decreased. In the hypothalamus miRNAs were both up- and down-regulated.

\subsection{Examples of the Consequences of Epigenetic Regulations in Sleep Disruption}

\subsubsection{Epigenetics of Sleep Disturbances and Metabolic Consequences}

Chronic loss of sleep, social jet lag, and shift work are the most common reasons that are linked to an elevated risk of metabolic disorders, such as type 2 diabetes, metabolic syndrome, and obesity [110-113]. A shift in the sleep time because of weekly environmental changes or a continuous five nights of short sleep is reported to elevate the risk of weight gain in healthy individuals [113, 114]. Metabolic perturbations follow a tissue-specific pattern in peripheral tissues such as skeletal muscle and adipose tissue $[115,116]$. It is also proposed that sleep loss can promote adverse catabolism and anabolism in a tissue-specific manner [117], e.g., loss of muscle mass $[118,119]$. However, the underlying molecular mechanisms are less investigated. A single night of sleep loss in humans was shown to induce tissue-specific transcriptional and DNA methylation changes in circadian clock genes [88], although the downstream tissue-specific impact on metabolic pathways was not determined.

In 2018 [87], the effects of acute sleep loss were investigated on tissue-specific alterations in the metabolic pathways, i.e., anabolic versus the catabolic state. This study hypothesized that acute sleep loss would promote adipogenesis, reflecting changes in DNA methylation. Samples from subcutaneous adipose tissue and skeletal muscle were obtained from healthy young men, following a night of sleep loss and a night of full sleep, for subsequent analysis [87]. This study showed the glycolytic pathway being down-regulated in skeletal muscle but upregulated in subcutaneous adipose tissue. Transcriptomic markers of inflammation were found in both tissues, and this was the first human evidence to demonstrate that acute sleep loss may re-program DNA methylation in adipose tissue, promoting adipogenesis in adipose tissue and catabolism in skeletal muscles [87]. These observations partially explain the underlying mechanisms of weight gain and sarcopenia following the disturbance in sleep and circadian rhythm [87]. These findings were consistent with the animal studies (rats) deprived of extended REM sleep, which demonstrated atrophy in only glycolytic and mixed muscles but not in oxidative muscles $[119,120]$. Insufficient sleep in middle-aged and older adults is found to be associated with lower skeletal muscle mass $[111,118]$. With the presence of catabolic markers in blood and urine, loss of sleep is also observed [116, 121]. Higher catabolism following an acute sleep loss might be due to the regulatory hormonal disruptions. Cortisol, a catabolic hormone, is elevated following an acute sleep loss while testosterone [122] and nocturnal growth hormones [123] are lowered.

Changes in DNA methylation were observed in the genes that were previously demonstrated in adipose tissue of obese and type 2 diabetic patients, just after losing one night's sleep. It remains to be elucidated whether other environmental factors such as diet, exercise, and stress could modulate or alter the duration of these changes towards a worsened or rather a protective state or not [87]. A recovery sleep during the weekends, however, failed to prevent metabolic dysregulation, according to a 2019 study [124]. In this study, Depner et al. [124] evaluated sleep, 
circadian timing, energy intake, weight gain, and insulin sensitivity during a period of 9 consecutive nights of insufficient sleep, followed by a weekend of ad libitum recovery sleep. Young, healthy individuals were divided into three groups: control, insufficient sleep without weekend recovery sleep, and insufficient sleep with weekend recovery sleep groups. The results presented that insufficient sleep delayed the circadian phase and increased the energy intake along with the body weight compared to the baseline. Weekend recovery sleep was not sufficient or effective in reversing the metabolic alterations caused by recurrent insufficient sleep. Also, a gender-related response was observed during the weekend recovery phase, where women showed lowered total sleep duration and a decreased energy intake of baseline levels when compared to men. This highlights the importance of including both females and males in sleeprelated studies associated with epigenetic factors. In addition, this study provided evidence that the general belief of weekend recovery sleep reversing the sleep-loss alterations might not be true in normalizing the metabolic dysregulation caused by recurrent insufficient sleep [124].

Pregnancy is known as a condition in which lifestyle is transiently affected. There are numerous recommendations and guidelines available for parents to maintain maternal mental and physical health with various choices of activities, including diet, exercise, and sleep [125-128]. A majority of pregnant women experience sleep disorders, including fragmented or inadequate sleep [127, 128]. Sleep fragmentation is reported, especially during the late gestation phase [129], and sleep disorders in pregnancy were also associated with increased gestational weight gain, pregnancy complications such as gestational diabetes mellitus, and adverse perinatal and post-natal outcomes. For example, intrauterine growth restriction, low birth weight, preterm birth, a child's risk of overweight and obesity [130-132] are proposed to occur in offspring through epigenetic modifications [133]. Although some mice studies have provided evidence for the role of epigenetic factors and mediating pathways during pregnancy, there is still a lack in human studies that link gestational sleep disruption with the cardio-metabolic health of the offspring. A 2015 study demonstrated that sex dimorphism existed in mice offspring following the late gestational sleep fragmentation [134]. In this study, only the male offspring had higher food intake, body weight, visceral fat mass, insulin resistance, and lower adiponectin levels. Dyslipidemia was, however, apparent in both sexes [134]. Another study by this group investigated the effects of sleep fragmentation during late gestation on the metabolic function and expression of adiponectin in visceral white adipose tissue of the mice offspring. Male offspring of mice in the sleep fragmented group was assessed, and an increase was observed in their food intake, body weight, visceral white adipose tissue mass, and insulin resistance while adiponectin expression was reduced in the visceral white adipose tissue. Several epigenetic markers were also identified on the adiponectin found in visceral white adipose tissue of adipocytes in a male mouse offspring along with a metabolic syndrome-like phenotype. This study highlighted the importance of an altered gestational environment that can cause long-lasting metabolic consequences for future generations [135]. Later in 2016, two other mice studies [136, 137] demonstrated that gestational sleep deprivation could elevate blood pressure in offspring through the autonomic regulation in cardiovascular and renal alterations [23, 24]. A recent study in humans has evaluated the association between gestational sleep deprivation, childhood adiposity, and cardio-metabolic health [130]. Data from two European cohorts were used to accommodate diversity in ethnic and demographic characteristics, and it was found that gestational sleep deprivation might be associated with an increased risk of overweight and higher blood pressure in offspring till the age 
of 11 years [130]. This study also showed that the association was more pronounced in girls than boys [130], which is in contrast with mice study. Along with sleep deprivation, the authors of this study also encourage further studies on sleep quality during pregnancy [130]. Also, there is a need for an official sleep recommendation for pregnant women; however, based on the findings of this study, sleep deprivation (i.e., sleep duration of $6 \mathrm{~h}$ and less) has to be avoided at any stage of pregnancy [130].

\subsubsection{Sleep Deprivation Alters Brain and Blood Phenome}

Analysis of both animal and selected human samples have provided evidence that sleep deprivation alters the transcriptome and methylome [42, 43, 88, 138-140]. In rats, sleep deprivation altered the brain transcriptome affecting protein synthesis, synaptic plasticity, and metabolism [138, 141]. Archer et al. [142] presented that mistiming sleep could reduce rhythmic transcripts and cause remarkable alterations in the transcriptome. The average methylation in the night-shift workers was significantly reduced compared to the dayshift workers [143, 144]. This implies that underlying mechanisms with negative consequences of chronic lack of sleep need greater attention towards the night-shift workers. Genetic risk factors are also reported in people having an intolerance towards shift work [145] and an association was found between job-related exhaustion and a variant of the melatonin receptor $1 \mathrm{~A}$ gene, proposing that the mechanism of changes in DNA methylation at the gene promoter are in response to the shift work [145]. In light of the value of studying DNA methylation for understanding mechanisms underlying insomnia, in 2019, Lahtinen et al. [146] investigated blood leukocytes to identify differentially methylated DNA in samples obtained from DILGOM, a sub-study of the population-based FINRISK along with a population that consisted of airline shift workers. This cross-sectional, genome-wide study identified a remarkable low level of DNA methylation (hypomethylation) in both cohorts associated with sleep loss [146]. A distinctive pattern was observed in individuals having sleep disturbances, where 399 differentially methylated positions were identified, out of which 327 were linked to the nervous system development pathway, which is also in line with the previous data, where DNA methylation induced by sleep disturbances was involved in synaptic plasticity and neuritogenesis [42]. It is worth mentioning that previous studies have analyzed DNA methylation in the brain tissue of rodents, whereas Lahtinen et al. [146] revealed these systemic changes in response to sleep disturbances in human blood samples. This shows that it is important to consider systemic sleep disturbance effects while selecting the right choice of sample for analysis.

Future studies must consider racial and ethnic disparities while designing epigenetic studies regarding sleep and sleep disruptions. An association analysis study consisting of a racially diverse population [147] measured DNA methylation in monocytes to identify whether a link exists between these markers and daytime sleepiness, and it was found that most significant DNA methylation was specific to African Americans [147].

\subsubsection{Irregular or Shorter Sleep Accelerates Epigenetic Aging}

A recent pilot study by Carskadon et al. [148] in young females identified that shorter or irregular sleep might advance epigenetic aging. In this study, 12 young women, defined as short or long sleepers, were studied for nine weeks. Blood samples were obtained to determine the effects 
of DNA methylation levels on epigenetic age. The results revealed that longer and regularly sleeping females had a lesser difference between their chronological and epigenetic age compared to those with shorter and irregular sleep. Thus, poor sleep was found to be associated with a marked acceleration of epigenetic aging [148]. Regular meditation has been suggested to slow down the epigenetic aging [149]. Also, exercise reduces DNA methylation at age-related CpG sites [150, 151], highlighting the value of studies on behavioral interventions in epigenetic mechanisms. This is particularly an interesting area since a review from 2018 [152] had discussed the potentials of epigenetic regulation of the adult dentate gyrus (DG) neurogenesis and the influence of sleep and epigenetic modifications on this neurogenesis. Evidence shows that cognitive and emotional processing and memory consolidation are affected by the neurogenesis, thereby suggesting ways to use sleep or epigenetic interventions as therapies for neurodegenerative and psychiatric disorders [152]. In light of the growing population of aged people and the prevalence of neurodegenerative and neuropsychiatric disorders in our societies, studying sleep-related neural processes and epigenetic mechanisms may facilitate novel approaches to prevent and treat these disorders.

\subsubsection{Role of Epigenetic Regulations in Sleep under the Influence of Other Lifestyle Factors}

Sleep is influenced by several other lifestyle factors [153], including diet, exercise, smoking, and medications. Further research is needed to understand the mechanisms underlying the effects of all these factors. The effects of diet are more commonly studied among these factors. High carbohydrate diets, along with the foods containing tryptophan, melatonin, and phytonutrients (e.g., cherries) were linked to improving sleep outcomes [154]. This effect is proposed to be exerted through serotonin and melatonin. Also, it is reported that after short-term sleep deprivation, melatonin can promote the proliferation of neural stem cells in the adult hippocampus, where evidence indicates that epigenetic regulators may be involved. A recent study [155] investigated the effect of melatonin treatment on a 96-hour sleep-deprived subject and analyzed the expression of epigenetic modulators. The results showed that the administration of melatonin under sleep-deprived conditions increased MECP2 expression but reduced SIRT1 expression in DG. Let-7b, mir-132, and mir-124 were highly expressed upon the administration of melatonin but were not modified by sleep deprivation. In the subgranular zone of the sleep-deprived group treated with melatonin, more number of Sox2+/5-Bromo-2'deoxyuridine (BrdU)+ cells were identified compared to the untreated group. These findings may support the notion that melatonin modifies the expression of epigenetic mediators, which in turn regulates the proliferation of neural progenitor cells in the adult DG under long-term sleepdeprived conditions. However, sleep-melatonin and its interaction with epigenetic factors need further investigation.

Coffee is a commonly consumed drink and is widely discussed for its related risks and benefits in health [156]. For example, heavy consumption of coffee can induce insomnia [156], and caffeine is known to reverse the negative effects of sleep deprivation while promoting prolonged wakefulness [157, 158]. Caffeine blocks adenosine from binding to its receptor, resulting in improved cognitive function and increased alertness $[159,160]$. DNA methylation is proposed to play a role in caffeine-health interaction [161]. Epigenetic studies of caffeine were mainly reported in animals [162-164], while the first study in humans was conducted by Chuang et al. in 2017 [165] 
to investigate whether coffee consumption induced epigenetic changes in humans. The results of this study suggested that coffee affected DNA methylation levels in blood immune cells [165]. Many of the differentially methylated CpGs related to coffee consumption were located in or near the genes that were associated with coffee-related chronic diseases, including the neurodegenerative diseases (e.g., Parkinson's Disease and Alzheimer disease). Interestingly, coffee is also known to be beneficial for these neurodegenerative disorders [166, 167]. However, one must consider that the study by Chuang et al. [165] included mixed race and gender and did not particularly focus on sleep. Therefore, the effects of caffeine on epigenetic modifications of sleep would need further investigation.

Other dietary components were also proposed to alter epigenetic pathways that might have potentially interacted with sleep. For example, dietary methyl donors (e.g., folate and choline) were proposed to promote DNA methylation and, in turn, increased promoter methylation was associated with transcriptional suppression [168]. Based on this, "epigenetic diets", were also proposed [169], but these diets were questionable since the term epigenetic diet was used for the diet, which was folate-rich as well [170].

Dietary components were also proposed to influence histone modification [171]. Gut-brain axis and bidirectional cross-talk were being investigated extensively in many human health conditions [153]. A diverse range of methods was applied to modulate the gut microbiome, including antibiotic therapy, fecal microbiota transplant, or dietary intervention, such as the use of probiotics [172]. Probiotics have shown promising results in many conditions, such as neurodegenerative disorders [173] and migraine [174]. Dietary factors can modify the gut microbiome through epigenetic pathways [175], and this might be applicable to sleep disorders as well.

Omic studies can be employed to investigate transcriptomics, proteomics, and metabolomics of sleep-diet interactions. Changes in the DNA methylation patterns, histone modifications, and regulatory RNA transcriptomics would broaden the spectrum to characterize and understand the complicated interaction between sleep and other lifestyle factors such as diet, in light of epigenetics, and this will eventually lead to a personalized medicine strategy [176]. However, this is challenging because multiple lifestyle factors are concurrently being tested. Epigenetics is also involved in a wide range of processes and can facilitate better adaptation to environmental factors and is not always associated with a negative outcome. Therefore, understanding how to modulate the epigenetic-related factors optimally may prove beneficial in coping and adaptative methods.

\section{Future Perspectives}

Studying epigenetic mechanisms of sleep disruption and its reversal is a fascinating and growing field, yet it is complicated and challenging to deal with. Although few studies have elucidated the roles and the epigenetic mechanisms of sleep disruption to some extent, our review positively provides the evidence for these as well. Further investigation of functional interactions between epigenetic factors and sleep disorders would help in understanding the nature of the interaction. It is desirable to understand if the interactions are causal, modulatory, or correlative. Along with the identification of epigenetic factors influencing sleep, we also need to consider investigations that focus on recovery or prevention of these alterations to restore the balance or normalize sleep disturbances. We need evidence provided by further research in a 
diverse range of models with different conditions related to the neurobiology of sleep, to identify whether epigenetic mechanisms, such as DNA methylation, are disturbed in such cases and if blocking the DNA methylation can reverse the condition. Interventions might range from simple modification strategies such as recovery sleep, diet, exercise to multidimensional or integrated strategies that include medications, coping, and adaptation strategies. However, one must also consider counterbalance risk and safety issues of modification strategies. Most experimental studies in humans and animals focus on acute controlled conditions, which are highly valuable, but chronic sleep alterations and reversal strategies may show a different pattern on the epigenome. Also, most studies focus on sleep loss, whereas sleepiness studies are equally important. Interestingly, some small changes in sleep may lead to unexpected epigenetic alterations, which are important to consider in study designs. For example, changes in the length of the day may influence the pattern of DNA methylation. Azzi et al. [177] kept mice under a day length of 22hour and 24-hour, and this small change of 2-hour difference revealed alterations in methylation patterns at promoter regions of $S C N$, leading to changes in gene expression. This supports the idea that DNA methylation might be a sensitive and rapidly occurring process. These alterations were, however, reversed when a cycle of 24-hour was extended over two weeks in this study [177], highlighting that DNA methylation might serve as an adaptive process that can be adjusted to environmental conditions, such as altered day length. Therefore, it can be assumed that DNA methylation might be beneficial in body coping strategies. This is an interesting finding as people living far north may show different patterns of DNA methylation at baseline levels and also be differentially affected in response to circadian changes.

Epigenetics can also be explored to help in the diagnosis or stratification of patients, where the expression of epigenetic markers in insomnia or sleepiness could be used as diagnostic criteria. These markers can also help with the optimal choice of pharmacological or non-pharmacological interventions [80]. If further evidence confirms a relationship between epigenetic changes and sleep disorders, then stimulation or inhibition of epigenetic markers may offer a novel strategy for the treatment or prevention of sleep disorders, which is valuable because current strategies applied in sleep disturbances [178-180] are only partially effective or carry side effects. Also, sleep disturbances are often comorbid, and this complexity makes therapeutic management even more challenging [80].

Omics have proved useful in studying many health-related conditions, such as cancer, metabolic disorders, or pain [181-183]. Integrative omic systems (genomics, proteomics, or metabolomics) would be beneficial in studying epigenetic mechanisms underlying sleep disruption, as it allows us to study the expression of markers at different interactive levels. In order to analyze the consequences of environmental influence [184], potential sleep-disturbing factors, such as high work demands, light exposure, job strain, noise, and shift schedules can be considered [185-187]. Isolated and integrated lifestyle factors related to epigenetics can bring new insight into interacting factors (such as diet, exercise, smoking, and stress) since they are unavoidable in real-life conditions.

Animal models have provided useful information on molecular mechanisms of sleep disorders, including narcolepsy, sleep apnea, restless legs syndrome, and insomnia [39]. DNA methylation, histone modifications, chromatin remodeling, non-coding RNA regulation, and RNA editing can be studied in these models $[188,189]$. However, the translatability of this data to humans must be considered carefully with factors such as race, sex, comorbid disorders, and concomitant 
medications, which can lead to proper designing of future studies. Hence, multimodal assessment and correlation analysis of objective and subjective markers related to sleep can enrich our understanding of underlying mechanisms and complexity of targeting. Also, different epigenetic elements must be considered to design future studies.

Considering the limited but promising findings and several open research avenues in this field, it is highly expected to witness rapidly emerging studies and evidence generation in the coming years on the role and significance of epigenetic regulation in sleep disruptions. Epigenetic studies for sleep disorders will not only enhance our understanding of the risks but also help in recognizing the importance of various environmental factors influencing the sleep disorders, and eventually modulating these factors may further help us in treating patients and providing preventive strategies.

\section{Author Contributions}

PG carried out the literature search and wrote this review.

\section{Funding}

None.

\section{Competing Interests}

The author has declared that no competing interests exist.

\section{References}

1. Keene AC, Duboue ER. The origins and evolution of sleep. J Exp Biol. 2018; 221.

2. Benington $\mathrm{JH}$, Heller HC. Restoration of brain energy metabolism as the function of sleep. Prog Neurobiol. 1995; 45: 347-360.

3. Mignot E. Why we sleep: the temporal organization of recovery. PLoS Biol. 2008; 6: e106.

4. Gomez-Gonzalez B, Dominguez-Salazar E, Hurtado-Alvarado G, Esqueda-Leon E, SantanaMiranda R, Rojas-Zamorano JA, et al. Role of sleep in the regulation of the immune system and the pituitary hormones. Ann N Y Acad Sci. 2012; 1261: 97-106.

5. Tononi G, Cirelli C. Sleep function and synaptic homeostasis. Sleep Med Rev. 2006; 10: 49-62.

6. Tononi G, Cirelli C. Sleep and the price of plasticity: from synaptic and cellular homeostasis to memory consolidation and integration. Neuron. 2014; 81: 12-34.

7. Ohayon M, Wickwire EM, Hirshkowitz M, Albert SM, Avidan A, Daly FJ, et al. National Sleep Foundation's sleep quality recommendations: First report. Sleep Health. 2017; 3: 6-19.

8. Watson NF, Badr MS, Belenky G, Bliwise DL, Buxton OM, Buysse D, et al. Recommended amount of sleep for a healthy adult: $A$ joint consensus statement of the American academy of sleep medicine and sleep research society. Sleep. 2015; 38: 843-844.

9. Hirshkowitz M, Whiton K, Albert SM, Alessi C, Bruni O, DonCarlos L, et al. National Sleep Foundation's sleep time duration recommendations: Methodology and results summary. Sleep Health. 2015; 1: 40-43.

10. Abel T, Havekes R, Saletin JM, Walker MP. Sleep, plasticity and memory from molecules to whole-brain networks. Curr Biol. 2013; 23: R774-788. 
11. Buzsaki G. Hippocampal sharp wave-ripple: A cognitive biomarker for episodic memory and planning. Hippocampus. 2015; 25: 1073-1188.

12. Diekelmann S, Born J. The memory function of sleep. Nat Rev Neurosci. 2010; 11: 114-126.

13. Qureshi IA, Mehler MF. Epigenetics of sleep and chronobiology. Curr Neurol Neurosci Rep. 2014; 14: 432.

14. Kudielka BM, Federenko IS, Hellhammer DH, Wust S. Morningness and eveningness: the free cortisol rise after awakening in "early birds" and "night owls". Biol Psychol. 2006; 72: 141-146.

15. Susman EJ, Dockray S, Schiefelbein VL, Herwehe S, Heaton JA, Dorn LD. Morningness/eveningness, morning-to-afternoon cortisol ratio, and antisocial behavior problems during puberty. Dev Psychol. 2007; 43: 811-822.

16. Ingram KK, Ay A, Kwon SB, Woods K, Escobar S, Gordon M, et al. Molecular insights into chronotype and time-of-day effects on decision-making. Sci Rep. 2016; 6: 29392.

17. Kalmbach DA, Schneider LD, Cheung J, Bertrand SJ, Kariharan T, Pack Al, et al. Genetic basis of chronotype in humans: Insights from three landmark GWAS. Sleep. 2017; 40.

18. Facer-Childs ER, Middleton B, Skene DJ, Bagshaw AP. Resetting the late timing of 'night owls' has a positive impact on mental health and performance. Sleep Med. 2019; 60: 236-247.

19. Etchegaray JP, Mostoslavsky R. Interplay between metabolism and epigenetics: A nuclear adaptation to environmental changes. Mol Cell. 2016; 62: 695-711.

20. Hardeland R, Madrid JA, Tan DX, Reiter RJ. Melatonin, the circadian multioscillator system and health: the need for detailed analyses of peripheral melatonin signaling. J Pineal Res. 2012; 52: 139-166.

21. Tsang $A H$, Astiz $M$, Friedrichs $M$, Oster $H$. Endocrine regulation of circadian physiology. J Endocrinol. 2016; 230: R1-R11.

22. Leliavski A, Dumbell R, Ott V, Oster H. Adrenal clocks and the role of adrenal hormones in the regulation of circadian physiology. J Biol Rhythms. 2015; 30: 20-34.

23. Rajaratnam SM, Arendt J. Health in a 24-h society. Lancet. 2001; 358: 999-1005.

24. Papazyan R, Zhang Y, Lazar MA. Genetic and epigenomic mechanisms of mammalian circadian transcription. Nat Struct Mol Biol. 2016; 23: 1045-1052.

25. Pallesen S, Sivertsen B, Nordhus IH, Bjorvatn B. A 10-year trend of insomnia prevalence in the adult Norwegian population. Sleep Med. 2014; 15: 173-179.

26. Kronholm E, Partonen T, Harma M, Hublin C, Lallukka T, Peltonen M, et al. Prevalence of insomnia-related symptoms continues to increase in the Finnish working-age population. J Sleep Res. 2016; 25: 454-457.

27. Liu Y, Wheaton AG, Chapman DP, Cunningham TJ, Lu H, Croft JB. Prevalence of healthy sleep duration among adults--United States, 2014. MMWR Morb Mortal Wkly Rep. 2016; 65: 137141.

28. Kronholm E, Laatikainen T, Peltonen M, Sippola R, Partonen T. Self-reported sleep duration, all-cause mortality, cardiovascular mortality and morbidity in Finland. Sleep Med. 2011; 12: 215-221.

29. Akerstedt T. Shift work and disturbed sleep/wakefulness. Occup Med (Lond). 2003; 53: 89-94.

30. Wright KP, Jr., Bogan RK, Wyatt JK. Shift work and the assessment and management of shift work disorder (SWD). Sleep Med Rev. 2013; 17: 41-54.

31. Flo E, Pallesen S, Mageroy N, Moen BE, Gronli J, Hilde Nordhus I, et al. Shift work disorder in nurses--assessment, prevalence and related health problems. PLoS One. 2012; 7: e33981. 
32. Di Milia L, Waage S, Pallesen S, Bjorvatn B. Shift work disorder in a random population sample--prevalence and comorbidities. PLoS One. 2013; 8: e55306.

33. Porkka-Heiskanen T, Zitting KM, Wigren HK. Sleep, its regulation and possible mechanisms of sleep disturbances. Acta Physiol (Oxf). 2013; 208: 311-328.

34. Hudec M, Dankova P, Solc R, Bettazova N, Cerna M. Epigenetic regulation of circadian rhythm and its possible role in diabetes mellitus. Int J Mol Sci. 2020; 21.

35. Krause AJ, Simon EB, Mander BA, Greer SM, Saletin JM, Goldstein-Piekarski AN, et al. The sleep-deprived human brain. Nat Rev Neurosci. 2017; 18: 404-418.

36. Zhao Z, Zhao X, Veasey SC. Neural consequences of chronic short sleep: Reversible or lasting? Front Neurol. 2017; 8: 235.

37. Van Someren EJ, Cirelli C, Dijk DJ, Van Cauter E, Schwartz S, Chee MW. Disrupted sleep: From molecules to cognition. J Neurosci. 2015; 35: 13889-13895.

38. Kristiansen ES, Nielsen LS, Christensen SS, Botvid SHC, Norgaard Poulsen J, Gazerani P. Sleep deprivation sensitizes human craniofacial muscles. Somatosens Mot Res. 2017; 34: 116-122.

39. Toth LA, Bhargava P. Animal models of sleep disorders. Comp Med. 2013; 63: 91-104.

40. Duan R, Liu X, Wang T, Wu L, Gao X, Zhang Z. Histone acetylation regulation in sleep deprivation-induced spatial memory impairment. Neurochem Res. 2016; 41: 2223-2232.

41. Narwade SC, Mallick BN, Deobagkar DD. Transcriptome analysis reveals altered expression of memory and neurotransmission associated genes in the rem sleep deprived rat brain. Front Mol Neurosci. 2017; 10: 67.

42. Massart R, Freyburger M, Suderman M, Paquet J, El Helou J, Belanger-Nelson E, et al. The genome-wide landscape of DNA methylation and hydroxymethylation in response to sleep deprivation impacts on synaptic plasticity genes. Transl Psychiatry. 2014; 4: e347.

43. Ventskovska O, Porkka-Heiskanen T, Karpova NN. Spontaneous sleep-wake cycle and sleep deprivation differently induce Bdnf1, Bdnf4 and Bdnf9a DNA methylation and transcripts levels in the basal forebrain and frontal cortex in rats. J Sleep Res. 2015; 24: 124-130.

44. Trivedi MS, Holger D, Bui AT, Craddock TJA, Tartar JL. Short-term sleep deprivation leads to decreased systemic redox metabolites and altered epigenetic status. PLoS One. 2017; 12: e0181978.

45. Nilsson EK, Bostrom AE, Mwinyi J, Schioth HB. Epigenomics of total acute sleep deprivation in relation to genome-wide DNA methylation profiles and RNA expression. OMICS. 2016; 20: 334-342.

46. Hala D, Huggett DB, Burggren WW. Environmental stressors and the epigenome. Drug Discov Today Technol. 2014; 12: e3-8.

47. Ladd-Acosta C. Epigenetic signatures as biomarkers of exposure. Curr Environ Health Rep. 2015; 2: 117-125.

48. Hughes V. Epigenetics: The sins of the father. Nature. 2014; 507: 22-24.

49. Gazerani P. Current evidence on the role of epigenetic mechanisms in migraine: The way forward to precision medicine. OBM Genetics. 2018; 2.

50. Chen Q, Yan W, Duan E. Epigenetic inheritance of acquired traits through sperm RNAs and sperm RNA modifications. Nat Rev Genet. 2016; 17: 733-743.

51. Hanson M, Muller R. Epigenetic inheritance and the responsibility for health in society. Lancet Diabetes Endocrinol. 2017; 5: 11-12. 
52. Messerschmidt DM. Should I stay or should I go: Protection and maintenance of DNA methylation at imprinted genes. Epigenetics. 2012; 7: 969-975.

53. Wang L, Zhang J, Duan J, Gao X, Zhu W, Lu X, et al. Programming and inheritance of parental DNA methylomes in mammals. Cell. 2014; 157: 979-991.

54. Peschansky VJ, Wahlestedt C. Non-coding RNAs as direct and indirect modulators of epigenetic regulation. Epigenetics. 2014; 9: 3-12.

55. Santamaria-Martos F, Benitez I, Ortega F, Zapater A, Giron C, Pinilla L, et al. Circulating microRNA profile as a potential biomarker for obstructive sleep apnea diagnosis. Sci Rep. 2019; 9: 13456.

56. Roser AE, Caldi Gomes L, Schunemann J, Maass F, Lingor P. Circulating miRNAs as diagnostic biomarkers for Parkinson's disease. Front Neurosci. 2018; 12: 625.

57. Gazerani P. Current evidence on potential uses of MicroRNA biomarkers for migraine: From diagnosis to treatment. Mol Diagn Ther. 2019; 23: 681-694.

58. Andersen HH, Duroux M, Gazerani P. Serum microrna signatures in migraineurs during attacks and in pain-free periods. Mol Neurobiol. 2016; 53: 1494-1500.

59. Andersen HH, Gazerani P. MicroRNAs and pain. In: Barbato C, Ruberti F, editors. Mapping of nervous system diseases via MicroRNAs. Frontiers in Neurotherapeutics Series: CRC Press; 2016. p. 183-204.

60. Kulis M, Esteller M. DNA methylation and cancer. Adv Genet. 2010; 70: 27-56.

61. Gama-Sosa MA, Slagel VA, Trewyn RW, Oxenhandler R, Kuo KC, Gehrke CW, et al. The 5methylcytosine content of DNA from human tumors. Nucleic Acids Res. 1983; 11: 6883-6894.

62. De Smet C, Loriot A. DNA hypomethylation in cancer: Epigenetic scars of a neoplastic journey. Epigenetics. 2010; 5: 206-213.

63. Estecio MR, Issa JP. Dissecting DNA hypermethylation in cancer. FEBS Lett. 2011; 585: 20782086.

64. Locke WJ, Guanzon D, Ma C, Liew YJ, Duesing KR, Fung KYC, et al. DNA methylation cancer biomarkers: Translation to the clinic. Front Genet. 2019; 10: 1150.

65. Ciccarone F, Tagliatesta S, Caiafa P, Zampieri M. DNA methylation dynamics in aging: How far are we from understanding the mechanisms? Mech Ageing Dev. 2018; 174: 3-17.

66. Martinez-Iglesias O, Carrera I, Carril JC, Fernandez-Novoa L, Cacabelos N, Cacabelos R. DNA methylation in neurodegenerative and cerebrovascular disorders. Int J Mol Sci. 2020; 21.

67. Sadakierska-Chudy A, Kostrzewa RM, Filip M. A comprehensive view of the epigenetic landscape part I: DNA methylation, passive and active DNA demethylation pathways and histone variants. Neurotox Res. 2015; 27: 84-97.

68. Weinhold B. Epigenetics: The science of change. Environ Health Perspect. 2006; 114: A160167.

69. Sadakierska-Chudy A, Filip M. A comprehensive view of the epigenetic landscape. Part II: Histone post-translational modification, nucleosome level, and chromatin regulation by ncRNAs. Neurotox Res. 2015; 27: 172-197.

70. Gibney ER, Nolan CM. Epigenetics and gene expression. Heredity (Edinb). 2010; 105: 4-13.

71. Macdonald WA. Epigenetic mechanisms of genomic imprinting: common themes in the regulation of imprinted regions in mammals, plants, and insects. Genet Res Int. 2012; 2012: 585024. 
72. Kalish JM, Jiang C, Bartolomei MS. Epigenetics and imprinting in human disease. Int J Dev Biol. 2014; 58: 291-298.

73. Harrington J, Lee-Chiong T. Basic biology of sleep. Dent Clin North Am. 2012; 56: 319-330.

74. Adams GC, Stoops MA, Skomro RP. Sleep tight: exploring the relationship between sleep and attachment style across the life span. Sleep Med Rev. 2014; 18: 495-507.

75. Khoury J, Doghramji K. Primary sleep disorders. Psychiatr Clin North Am. 2015; 38: 683-704.

76. Ramar K, Olson EJ. Management of common sleep disorders. Am Fam Physician. 2013; 88: 231-238.

77. Jagannath A, Taylor L, Wakaf Z, Vasudevan SR, Foster RG. The genetics of circadian rhythms, sleep and health. Hum Mol Genet. 2017; 26: R128-R138.

78. Chong SYC, Xin L, Ptacek LJ, Fu YH. Disorders of sleep and circadian rhythms. Handb Clin Neurol. 2018; 148: 531-538.

79. Chen YC, Hsu PY, Hsiao CC, Lin MC. Epigenetics: A potential mechanism involved in the pathogenesis of various adverse consequences of obstructive sleep apnea. Int J Mol Sci. 2019; 20.

80. Morales-Lara D, De-la-Pena C, Murillo-Rodriguez E. Dad's snoring may have left molecular scars in your DNA: The emerging role of epigenetics in sleep disorders. Mol Neurobiol. 2018; 55: 2713-2724.

81. Calic A, Peterlin B. Epigenetics and Bruxism: Possible Role of Epigenetics in the Etiology of Bruxism. Int J Prosthodont. 2015; 28: 594-599.

82. Murray BJ. A practical approach to excessive daytime sleepiness: A focused review. Can Respir J. 2016; 2016: 4215938.

83. Kay-Stacey M, Attarian H. Advances in the management of chronic insomnia. BMJ. 2016; 354 : i2123.

84. Wong CC, Parsons MJ, Lester KJ, Burrage J, Eley TC, Mill J, et al. Epigenome-Wide DNA methylation analysis of monozygotic twins discordant for diurnal preference. Twin Res Hum Genet. 2015; 18: 662-669.

85. Feng D, Lazar MA. Clocks, metabolism, and the epigenome. Mol Cell. 2012; 47: 158-167.

86. Gaine ME, Chatterjee $S$, Abel T. Sleep deprivation and the epigenome. Front Neural Circuits. 2018; 12: 14.

87. Cedernaes J, Schonke M, Westholm JO, Mi J, Chibalin A, Voisin S, et al. Acute sleep loss results in tissue-specific alterations in genome-wide DNA methylation state and metabolic fuel utilization in humans. Sci Adv. 2018; 4: eaar8590.

88. Cedernaes J, Osler ME, Voisin S, Broman JE, Vogel H, Dickson SL, et al. Acute sleep loss induces tissue-specific epigenetic and transcriptional alterations to circadian clock genes in men. J Clin Endocrinol Metab. 2015; 100: E1255-1261.

89. Huang $H$, Zhu Y, Eliot MN, Knopik VS, McGeary JE, Carskadon MA, et al. Combining human epigenetics and sleep studies in caenorhabditis elegans: A cross-species approach for finding conserved genes regulating sleep. Sleep. 2017; 40.

90. Zhu Y, Stevens RG, Hoffman AE, Tjonneland A, Vogel UB, Zheng T, et al. Epigenetic impact of long-term shiftwork: pilot evidence from circadian genes and whole-genome methylation analysis. Chronobiol Int. 2011; 28: 852-861. 
91. Moller-Levet CS, Archer SN, Bucca G, Laing EE, Slak A, Kabiljo R, et al. Effects of insufficient sleep on circadian rhythmicity and expression amplitude of the human blood transcriptome. Proc Natl Acad Sci U S A. 2013; 110: E1132-1141.

92. Greer EL, Shi Y. Histone methylation: A dynamic mark in health, disease and inheritance. Nat Rev Genet. 2012; 13: 343-357.

93. Murillo-Rodriguez E, Arankowsky-Sandoval G, Barros JA, Rocha NB, Yamamoto T, Machado S, et al. Sleep and neurochemical modulation by DZNep and GSK-J1: Potential link with histone methylation status. Front Neurosci. 2019; 13: 237.

94. von Schantz M. Phenotypic effects of genetic variability in human clock genes on circadian and sleep parameters. J Genet. 2008; 87: 513-519.

95. Guzman-Marin R, Ying Z, Suntsova N, Methippara M, Bashir T, Szymusiak R, et al. Suppression of hippocampal plasticity-related gene expression by sleep deprivation in rats. J Physiol. 2006; 575: 807-819.

96. Lekka E, Hall J. Noncoding RNAs in disease. FEBS Lett. 2018; 592: 2884-2900.

97. Maass PG, Luft FC, Bahring S. Long non-coding RNA in health and disease. J Mol Med (Berl). 2014; 92: 337-346.

98. Whitehead J, Pandey GK, Kanduri C. Regulation of the mammalian epigenome by long noncoding RNAs. Biochim Biophys Acta. 2009; 1790: 936-947.

99. Mills JD, Ward M, Chen BJ, Iyer AM, Aronica E, Janitz M. LINC00507 Is specifically expressed in the primate cortex and has age-dependent expression patterns. J Mol Neurosci. 2016; 59: 431-439.

100.Powell WT, Coulson RL, Crary FK, Wong SS, Ach RA, Tsang P, et al. A Prader-Willi locus IncRNA cloud modulates diurnal genes and energy expenditure. Hum Mol Genet. 2013; 22: 43184328.

101.Davis CJ, Taishi P, Honn KA, Koberstein JN, Krueger JM. P2X7 receptors in body temperature, locomotor activity, and brain mRNA and IncRNA responses to sleep deprivation. Am J Physiol Regul Integr Comp Physiol. 2016; 311: R1004-R1012.

102.Ng SY, Lin L, Soh BS, Stanton LW. Long noncoding RNAs in development and disease of the central nervous system. Trends Genet. 2013; 29: 461-468.

103.Aksoy-Aksel A, Zampa F, Schratt G. MicroRNAs and synaptic plasticity--a mutual relationship. Philos Trans R Soc Lond B Biol Sci. 2014; 369.

104.Ye Y, Xu H, Su X, He X. Role of MicroRNA in governing synaptic plasticity. Neural Plast. 2016; 2016: 4959523.

105.Davis CJ, Clinton JM, Taishi P, Bohnet SG, Honn KA, Krueger JM. MicroRNA 132 alters sleep and varies with time in brain. J Appl Physiol (1985). 2011; 111: 665-672.

106.Davis CJ, Clinton JM, Krueger JM. MicroRNA 138, let-7b, and 125a inhibitors differentially alter sleep and EEG delta-wave activity in rats. J Appl Physiol (1985). 2012; 113: 1756-1762.

107.Davis CJ, Bohnet SG, Meyerson JM, Krueger JM. Sleep loss changes microRNA levels in the brain: A possible mechanism for state-dependent translational regulation. Neurosci Lett. 2007; 422: 68-73.

108.Saus E, Soria V, Escaramis G, Vivarelli F, Crespo JM, Kagerbauer B, et al. Genetic variants and abnormal processing of pre-miR-182, a circadian clock modulator, in major depression patients with late insomnia. Hum Mol Genet. 2010; 19: 4017-4025. 
109.Mongrain V, Hernandez SA, Pradervand S, Dorsaz S, Curie T, Hagiwara G, et al. Separating the contribution of glucocorticoids and wakefulness to the molecular and electrophysiological correlates of sleep homeostasis. Sleep. 2010; 33: 1147-1157.

110.Cappuccio FP, D'Elia L, Strazzullo P, Miller MA. Quantity and quality of sleep and incidence of type 2 diabetes: A systematic review and meta-analysis. Diabetes Care. 2010; 33: 414-420.

111.Cappuccio FP, Taggart FM, Kandala NB, Currie A, Peile E, Stranges S, et al. Meta-analysis of short sleep duration and obesity in children and adults. Sleep. 2008; 31: 619-626.

112.Wong PM, Hasler BP, Kamarck TW, Muldoon MF, Manuck SB. Social jetlag, chronotype, and cardiometabolic risk. J Clin Endocrinol Metab. 2015; 100: 4612-4620.

113. Roenneberg T, Allebrandt KV, Merrow M, Vetter C. Social jetlag and obesity. Curr Biol. 2012; 22: 939-943.

114.Spaeth AM, Dinges DF, Goel N. Effects of experimental sleep restriction on weight gain, caloric intake, and meal timing in healthy adults. Sleep. 2013; 36: 981-990.

115. Rao MN, Neylan TC, Grunfeld C, Mulligan K, Schambelan M, Schwarz JM. Subchronic sleep restriction causes tissue-specific insulin resistance. J Clin Endocrinol Metab. 2015; 100: 16641671.

116.Bell LN, Kilkus JM, Booth JN, 3rd, Bromley LE, Imperial JG, Penev PD. Effects of sleep restriction on the human plasma metabolome. Physiol Behav. 2013; 122: 25-31.

117. Nedeltcheva AV, Kilkus JM, Imperial J, Schoeller DA, Penev PD. Insufficient sleep undermines dietary efforts to reduce adiposity. Ann Intern Med. 2010; 153: 435-441.

118.Buchmann N, Spira D, Norman K, Demuth I, Eckardt R, Steinhagen-Thiessen E. Sleep, muscle mass and muscle function in older people. Dtsch Arztebl Int. 2016; 113: 253-260.

119. Monico-Neto M, Giampa SQ, Lee KS, de Melo CM, Souza Hde S, Dattilo M, et al. Negative energy balance induced by paradoxical sleep deprivation causes multicompartmental changes in adipose tissue and skeletal muscle. Int J Endocrinol. 2015; 2015: 908159.

120. de Sa Souza H, Antunes HKM, Dattilo M, Lee KS, Monico-Neto M, de Campos Giampa SQ, et al. Leucine supplementation is anti-atrophic during paradoxical sleep deprivation in rats. Amino Acids. 2016; 48: 949-957.

121.Giskeodegard GF, Davies SK, Revell VL, Keun H, Skene DJ. Diurnal rhythms in the human urine metabolome during sleep and total sleep deprivation. Sci Rep. 2015; 5: 14843.

122.Leproult R, Van Cauter E. Effect of 1 week of sleep restriction on testosterone levels in young healthy men. JAMA. 2011; 305: 2173-2174.

123.Sassin JF, Parker DC, Mace JW, Gotlin RW, Johnson LC, Rossman LG. Human growth hormone release: Relation to slow-wave sleep and sleep-walking cycles. Science. 1969; 165: 513-515.

124.Depner CM, Melanson EL, Eckel RH, Snell-Bergeon JK, Perreault L, Bergman BC, et al. Ad libitum weekend recovery sleep fails to prevent metabolic dysregulation during a repeating pattern of insufficient sleep and weekend recovery sleep. Curr Biol. 2019; 29: 957-967 e954.

125.Davenport MH, Meah VL, Ruchat SM, Davies GA, Skow RJ, Barrowman N, et al. Impact of prenatal exercise on neonatal and childhood outcomes: A systematic review and metaanalysis. Br J Sports Med. 2018; 52: 1386-1396.

126. Rogozinska E, Marlin N, Jackson L, Rayanagoudar G, Ruifrok AE, Dodds J, et al. Effects of antenatal diet and physical activity on maternal and fetal outcomes: individual patient data meta-analysis and health economic evaluation. Health Technol Assess. 2017; 21: 1-158. 
127. Mindell JA, Cook RA, Nikolovski J. Sleep patterns and sleep disturbances across pregnancy. Sleep Med. 2015; 16: 483-488.

128. Ferraro ZM, Chaput JP, Gruslin A, Adamo KB. The potential value of sleep hygiene for a healthy pregnancy: A brief review. ISRN Family Med. 2014; 2014: 928293.

129.Silvestri R, Arico I. Sleep disorders in pregnancy. Sleep Sci. 2019; 12: 232-239.

130. Harskamp-van Ginkel MW, lerodiakonou D, Margetaki K, Vafeiadi M, Karachaliou M, Kogevinas $M$, et al. Gestational sleep deprivation is associated with higher offspring body mass index and blood pressure. Sleep. 2020.

131. Reutrakul S, Anothaisintawee T, Herring SJ, Balserak BI, Marc I, Thakkinstian A. Short sleep duration and hyperglycemia in pregnancy: Aggregate and individual patient data metaanalysis. Sleep Med Rev. 2018; 40: 31-42.

132. Oostvogels A, Hof MHP, Gademan MGJ, Roseboom TJ, Stronks K, Vrijkotte TGM. Does maternal pre-pregnancy overweight or obesity influence offspring's growth patterns from birth up to 7 years? The ABCD-study. Early Hum Dev. 2017; 113: 62-70.

133.Kawai T, Yamada T, Abe K, Okamura K, Kamura H, Akaishi R, et al. Increased epigenetic alterations at the promoters of transcriptional regulators following inadequate maternal gestational weight gain. Sci Rep. 2015; 5: 14224.

134. Khalyfa A, Carreras A, Almendros I, Hakim F, Gozal D. Sex dimorphism in late gestational sleep fragmentation and metabolic dysfunction in offspring mice. Sleep. 2015; 38: 545-557.

135.Khalyfa A, Mutskov V, Carreras A, Khalyfa AA, Hakim F, Gozal D. Sleep fragmentation during late gestation induces metabolic perturbations and epigenetic changes in adiponectin gene expression in male adult offspring mice. Diabetes. 2014; 63: 3230-3241.

136. Raimundo JR, Bergamaschi CT, Campos RR, Palma BD, Tufik S, Gomes GN. Autonomic and renal alterations in the offspring of sleep-restricted mothers during late pregnancy. Clinics (Sao Paulo). 2016; 71: 521-527.

137.Argeri R, Nishi EE, Volpini RA, Palma BD, Tufik S, Gomes GN. Sleep restriction during pregnancy and its effects on blood pressure and renal function among female offspring. Physiol Rep. 2016; 4.

138. Cirelli C, Tononi G. Gene expression in the brain across the sleep-waking cycle. Brain Res. 2000; 885: 303-321.

139. Benedict C, Cedernaes J, Giedraitis V, Nilsson EK, Hogenkamp PS, Vagesjo E, et al. Acute sleep deprivation increases serum levels of neuron-specific enolase (NSE) and S100 calcium binding protein B (S-100B) in healthy young men. Sleep. 2014; 37: 195-198.

140.Skuladottir GV, Nilsson EK, Mwinyi J, Schioth HB. One-night sleep deprivation induces changes in the DNA methylation and serum activity indices of stearoyl-CoA desaturase in young healthy men. Lipids Health Dis. 2016; 15: 137.

141.Cirelli C, Gutierrez CM, Tononi G. Extensive and divergent effects of sleep and wakefulness on brain gene expression. Neuron. 2004; 41: 35-43.

142.Archer SN, Laing EE, Moller-Levet CS, van der Veen DR, Bucca G, Lazar AS, et al. Mistimed sleep disrupts circadian regulation of the human transcriptome. Proc Natl Acad Sci U S A. 2014; 111: E682-691.

143. Bhatti P, Zhang Y, Song X, Makar KW, Sather CL, Kelsey KT, et al. Nightshift work and genomewide DNA methylation. Chronobiol Int. 2015; 32: 103-112. 
144.Adams CD, Jordahl KM, Copeland W, Mirick DK, Song X, Sather CL, et al. Nightshift work, chronotype, and genome-wide DNA methylation in blood. Epigenetics. 2017; 12: 833-840.

145.Sulkava S, Ollila HM, Alasaari J, Puttonen S, Harma M, Viitasalo K, et al. Common genetic variation near melatonin receptor 1 a gene linked to job-related exhaustion in shift workers. Sleep. 2017; 40.

146. Lahtinen A, Puttonen S, Vanttola P, Viitasalo K, Sulkava S, Pervjakova N, et al. A distinctive DNA methylation pattern in insufficient sleep. Sci Rep. 2019; 9: 1193.

147. Barfield R, Wang H, Liu Y, Brody JA, Swenson B, Li R, et al. Epigenome-wide association analysis of daytime sleepiness in the Multi-Ethnic Study of Atherosclerosis reveals AfricanAmerican-specific associations. Sleep. 2019; 42.

148.Carskadon MA, Chappell KR, Barker DH, Hart AC, Dwyer K, Gredvig-Ardito C, et al. A pilot prospective study of sleep patterns and DNA methylation-characterized epigenetic aging in young adults. BMC Res Notes. 2019; 12: 583.

149.Chaix R, Alvarez-Lopez MJ, Fagny M, Lemee L, Regnault B, Davidson RJ, et al. Epigenetic clock analysis in long-term meditators. Psychoneuroendocrinology. 2017; 85: 210-214.

150.Rea IM. Towards ageing well: Use it or lose it: Exercise, epigenetics and cognition. Biogerontology. 2017; 18: 679-691.

151.Unnikrishnan A, Freeman WM, Jackson J, Wren JD, Porter H, Richardson A. The role of DNA methylation in epigenetics of aging. Pharmacol Ther. 2019; 195: 172-185.

152.Akers KG, Cherasse Y, Fujita Y, Srinivasan S, Sakurai T, Sakaguchi M. Concise review: Regulatory influence of sleep and epigenetics on adult hippocampal neurogenesis and cognitive and emotional function. Stem Cells. 2018; 36: 969-976.

153. Mutch DM, Zulyniak MA, Rudkowska I, Tejero ME. Lifestyle genomics: Addressing the multifactorial nature of personalized health. Lifestyle Genom. 2018; 11: 1-8.

154.Binks H, G EV, Gupta C, Irwin C, Khalesi S. Effects of diet on sleep: A narrative review. Nutrients. 2020; 12.

155.Hinojosa-Godinez A, Jave-Suarez LF, Flores-Soto M, Galvez-Contreras AY, Luquin S, OregonRomero $\mathrm{E}$, et al. Melatonin modifies SOX2(+) cell proliferation in dentate gyrus and modulates SIRT1 and MECP2 in long-term sleep deprivation. Neural Regen Res. 2019; 14: 1787-1795.

156.Butt MS, Sultan MT. Coffee and its consumption: Benefits and risks. Crit Rev Food Sci Nutr. 2011; 51: 363-373.

157. Wadhwa M, Sahu S, Kumari P, Kauser H, Ray K, Panjwani U. Caffeine and modafinil given during $48 \mathrm{~h}$ sleep deprivation modulate object recognition memory and synaptic proteins in the hippocampus of the rat. Behav Brain Res. 2015; 294: 95-101.

158.Crawford C, Teo L, Lafferty L, Drake A, Bingham JJ, Gallon MD, et al. Caffeine to optimize cognitive function for military mission-readiness: A systematic review and recommendations for the field. Nutr Rev. 2017; 75: 17-35.

159. Fredholm BB, Battig K, Holmen J, Nehlig A, Zvartau EE. Actions of caffeine in the brain with special reference to factors that contribute to its widespread use. Pharmacol Rev. 1999; 51: 83-133.

160.Pasman WJ, Boessen R, Donner Y, Clabbers N, Boorsma A. Effect of caffeine on attention and alertness measured in a home-setting, using web-based cognition tests. JMIR Res Protoc. 2017; 6: e169. 
161.Petronis A. Epigenetics as a unifying principle in the aetiology of complex traits and diseases. Nature. 2010; 465: 721-727.

162.Ping J, Wang JF, Liu L, Yan YE, Liu F, Lei YY, et al. Prenatal caffeine ingestion induces aberrant DNA methylation and histone acetylation of steroidogenic factor 1 and inhibits fetal adrenal steroidogenesis. Toxicology. 2014; 321: 53-61.

163. Buscariollo DL, Fang X, Greenwood V, Xue H, Rivkees SA, Wendler CC. Embryonic caffeine exposure acts via $\mathrm{A} 1$ adenosine receptors to alter adult cardiac function and DNA methylation in mice. PLoS One. 2014; 9: e87547.

164.Wu DM, He Z, Ma LP, Wang LL, Ping J, Wang H. Increased DNA methylation of scavenger receptor class $B$ type I contributes to inhibitory effects of prenatal caffeine ingestion on cholesterol uptake and steroidogenesis in fetal adrenals. Toxicol Appl Pharmacol. 2015; 285: 89-97.

165.Chuang YH, Quach A, Absher D, Assimes T, Horvath S, Ritz B. Coffee consumption is associated with DNA methylation levels of human blood. Eur J Hum Genet. 2017; 25: 608-616.

166.Tellone E, Galtieri A, Russo A, Ficarra S. Protective effects of the caffeine against neurodegenerative diseases. Curr Med Chem. 2019; 26: 5137-5151.

167. Kolahdouzan M, Hamadeh MJ. The neuroprotective effects of caffeine in neurodegenerative diseases. CNS Neurosci Ther. 2017; 23: 272-290.

168. Bhutani N, Burns DM, Blau HM. DNA demethylation dynamics. Cell. 2011; 146: 866-872.

169. Hardy TM, Tollefsbol TO. Epigenetic diet: Impact on the epigenome and cancer. Epigenomics. 2011; 3: 503-518.

170.Fila M, Chojnacki C, Chojnacki J, Blasiak J. Is an "Epigenetic Diet" for migraines justified? The case of folate and dna methylation. Nutrients. 2019; 11.

171. Haberland $\mathrm{M}$, Montgomery RL, Olson EN. The many roles of histone deacetylases in development and physiology: Implications for disease and therapy. Nat Rev Genet. 2009; 10: 32-42.

172.Sasmita AO. Modification of the gut microbiome to combat neurodegeneration. Rev Neurosci. 2019; 30: 795-805.

173.Gazerani P. Probiotics for Parkinson's disease. Int J Mol Sci. 2019; 20.

174.Gazerani P. Migraine and diet. Nutrients. 2020; 12.

175. Hullar MA, Fu BC. Diet, the gut microbiome, and epigenetics. Cancer J. 2014; 20: 170-175.

176.de Toro-Martin J, Arsenault BJ, Despres JP, Vohl MC. Precision nutrition: A review of personalized nutritional approaches for the prevention and management of metabolic syndrome. Nutrients. 2017; 9.

177.Azzi A, Dallmann R, Casserly A, Rehrauer H, Patrignani A, Maier B, et al. Circadian behavior is light-reprogrammed by plastic DNA methylation. Nat Neurosci. 2014; 17: 377-382.

178.Szabadi E. Selective targets for arousal-modifying drugs: Implications for the treatment of sleep disorders. Drug Discov Today. 2014; 19: 701-708.

179.Krystal AD, Prather AA, Ashbrook LH. The assessment and management of insomnia: An update. World Psychiatry. 2019; 18: 337-352.

180.Riemann D, Baglioni C, Bassetti C, Bjorvatn B, Dolenc Groselj L, Ellis JG, et al. European guideline for the diagnosis and treatment of insomnia. J Sleep Res. 2017; 26: 675-700.

181. Hasin Y, Seldin M, Lusis A. Multi-omics approaches to disease. Genome Biol. 2017; 18: 83. 
182.Karczewski KJ, Snyder MP. Integrative omics for health and disease. Nat Rev Genet. 2018; 19 : 299-310.

183.Gazerani P, Vinterhøj HSH. 'Omics': An emerging field in pain research and management. Future Neurology. 2016 11: 255-265.

184.Tinarelli F, Garcia-Garcia C, Nicassio F, Tucci V. Parent-of-origin genetic background affects the transcriptional levels of circadian and neuronal plasticity genes following sleep loss. Philos Trans R Soc Lond B Biol Sci. 2014; 369: 20120471.

185. Holt JB, Zhang X, Sizov N, Croft JB. Airport noise and self-reported sleep insufficiency, United States, 2008 and 2009. Prev Chronic Dis. 2015; 12: E49.

186. Linton SJ, Kecklund G, Franklin KA, Leissner LC, Sivertsen B, Lindberg E, et al. The effect of the work environment on future sleep disturbances: A systematic review. Sleep Med Rev. 2015; 23: 10-19.

187. Reid KJ, Abbott SM. Jet lag and shift work disorder. Sleep Med Clin. 2015; 10: 523-535.

188. Doherty TS, Roth TL. Insight from animal models of environmentally driven epigenetic changes in the developing and adult brain. Dev Psychopathol. 2016; 28: 1229-1243.

189.Schuebel K, Gitik M, Domschke K, Goldman D. Making sense of epigenetics. Int J Neuropsychopharmacol. 2016; 19.

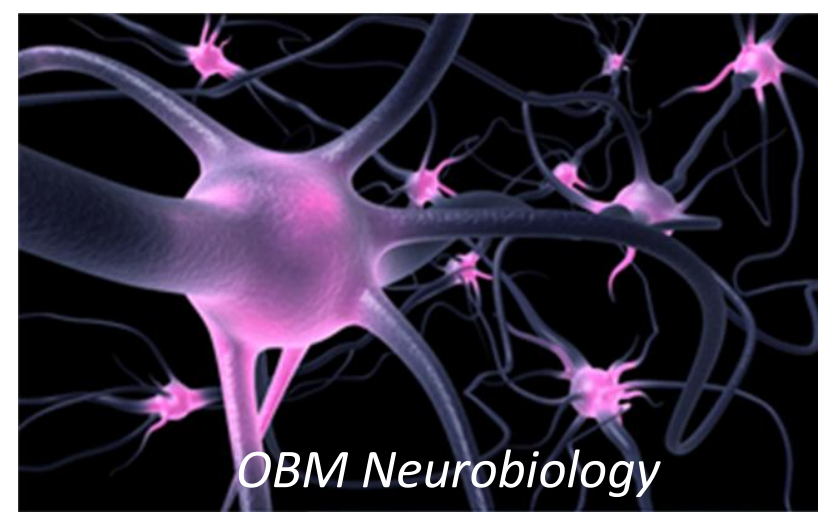

Enjoy OBM Neurobiology by:

1. Submitting a manuscript

2. Joining volunteer reviewer bank

3. Joining Editorial Board

4. Guest editing a special issue

For more details, please visit:

http://www.lidsen.com/journals/neurobiology 